\title{
NOVO SER TÃO VAZIO: AVALIAÇÃO DA GESTÃO DO PLANO DE MANEJO DA APA DE POUSO ALTO, GOIAS
}

\author{
NOVO SER TÃO VAZIO: EVALUATION OF THE \\ MANAGEMENT PLAN OF APA POUSO ALTO, GOIAS
}

\section{Juliana Guedes}

Pontifícia Universidade Católica do Rio de Janeiro, graduandas em Geografia e Meio Ambiente. E-mail:

julianaguedesms@gmail.com

Alexandra Loureiro Universidade Federal do Estado do Rio de Janeiro, graduanda em Ciências Ambientais. E-mail:

alexandracloureiro@outlook.com

\section{Resumo}

Este artigo retrata os desafios da gestão territorial de uma unidade de conservação abordada como uma política pública ambiental. Instigado pelo documentário "Ser Tão Velho Cerrado", o estudo tem como objeto de análise o Plano de Manejo da APA de Pouso Alto, localizada na Chapada dos Veadeiros no estado de Goiás. O objetivo geral é o estudo e análise da gestão na elaboração e na implementação do Plano de Manejo da APA e, por conseguinte, na sua gestão territorial. Como modelo de análise, utilizou-se a abordagem da Marta Arretche juntamente ao ciclo de políticas públicas, a fim de fornecer detalhes para a política em estudo. Compreende-se que o desequilíbrio de poder e influências de habitantes da APA são determinantes para a dificuldade de manutenção de uma Unidade de Conservação sustentável eficaz que garanta a conservação ambiental e os direitos das comunidades tradicionais locais.

Palavras-chave: gestão territorial, Plano de Manejo, APA de Pouso Alto, Chapada dos Veadeiros, políticas públicas.

\begin{abstract}
This article portrays the challenges of territorial management of a conservation unit approached as a public environmental policy. Instigated by the documentary "Ser Tão Velho Cerrado", the study has as object of analysis the Management Plan of the APA of Pouso Alto, located in Chapada dos Veadeiros in the state of Goiás. The general objective is the study and analysis of the management in the elaboration and implementation of the APA's Management Plan and, consequently, in its territorial management. As an analysis model, Marta Arretche's approach was used together with the public policy cycle in order to provide details for the policy in study. It is understood that the imbalance of power and influence of APA inhabitants are determinant to the difficulty of maintaining an effective sustainable Conservation Unit that guarantees environmental conservation and the rights of local traditional communities.
\end{abstract}

Keywords: territorial management, Management Plan, APA de Pouso Alto, Chapada dos Veadeiros, public policies. 


\title{
INTRODUÇÃO
}

O estudo das políticas públicas pela Ciência Política em meados dos anos 50, iniciado por seu pai fundador Harold Lasswell, desenvolveu o campo científico responsável por um novo modo de observar e entender as ações estatais. Conhecido como "Policy Analysis", buscava-se imprimir o entendimento de uma lógica de ação racional pública materializada na forma de políticas públicas em suas mais variadas áreas de influências na sociedade. O que se tem, então, é uma inter-relação entre Estado, política, economia e sociedade. Assim como bem aborda Celina Souza (2006), ao permear diversas disciplinas de interesse social, abarcando na multidisciplinaridade do debate sobre políticas públicas.

A partir desse pressuposto, essa subárea da Ciência Política pretende entender melhor como e porque tais medidas foram idealizadas por um governo, tal qual outras deixaram de ser materializadas. Busca-se responder a questões sobre a centralidade na implementação de certa política pública, assim como a abordagem de ideias e valores políticos, coalizões de defesa, conflitos institucionais etc. Nesse contexto, o que se pretende realizar é uma análise do objeto de estudo, o Plano de Manejo da APA de Pouso Alto, localizada na Chapada dos Veadeiros no estado de Goiás. Entendendo como análise a abordagem de Marta Arretche:

\begin{abstract}
"Por análise de políticas públicas, entende-se o exame da engenharia institucional e dos traços constitutivos dos programas. Qualquer política pública pode ser formulada e implementada de diversos modos. Digamos, as possibilidades de desenho institucional de uma política nacional de saúde, por exemplo, são as mais diversas do ponto de vista das formas de relação entre setor público e setor privado, das formas de financiamento, das modalidades de prestação de serviços etc. A análise de políticas públicas busca reconstituir estas diversas características, de forma a apreendê-las em um todo coerente e compreensível. " (ARRETCHE, p. 127, 2013)
\end{abstract}

Para a instrumentalização da análise das políticas públicas, torna-se imprescindível pontuar qual modelo de análise será realizado. Ao encontro de Eduardo Marques (2013), acompanhado de Hill e Hupe (2009), entendemos a importância da abordagem do ciclo das políticas públicas como uma ferramenta capaz de fornecer detalhes sobre o mapeamento de tal política. Defendido por Souza (2006), o ciclo das políticas públicas é um aporte deliberativo instituído por um processo dinâmico constituído, resumidamente, por 6 etapas: identificação do problema, formação da agenda, formulação de alternativas, decisão política, implementação e avaliação. 
A identificação do problema é definida pela discrepância entre uma situação real existente e como esta deveria ser idealizada segundo a sociedade. Esta etapa só é concebida como problema público se houver sua identificação por diferentes atores sociais, sua delimitação e a possibilidade de resolvê-lo. A formação da agenda é feita pelo conjunto dos problemas considerados relevantes e ainda categorizada em agenda política - problema merecedor de intervenção pública - e agenda institucional - problema já enfrentado pelo poder público. A representatividade dos grupos interessados em negociar, reivindicar e pressionar a inclusão de seus problemas nesta etapa é fundamental. A formulação de alternativas é feita por grupos de especialistas que apresentam propostas de soluções para resolver os respectivos problemas, é, então, momento de manifestação de conflitos entre os agentes. A tomada de decisão política evidencia os interesses dos tomadores de decisão, no caso, o Estado, e de que maneira os problemas se ajustam às soluções encontradas, uma vez que nem todas as intenções são contempladas. A implementação é o momento de concretização das soluções, sendo necessário o monitoramento para elucidar obstáculos e falhas provenientes de tal ação. Finalmente, a avaliação "consiste na mensuração e análise dos efeitos produzidos na sociedade pelas políticas públicas" (SANTOS et. al, 2011).

O que se pretende apresentar nas próximas páginas é de que forma a política pública ambiental na região da APA de Pouso Alto se deu, buscando analisar os conflitos e dificuldades na gestão de seu Plano de Manejo. Para isso, em primeiro lugar discutiremos as medidas ambientais brasileiras e, posteriormente, as características fundamentais da APA de Pouso Alto. Em seguida, analisaremos as relações de valores e interesses territorializados nesta área que limitam a construção eficaz desta política pública e transcendem a ação governamental, principalmente quanto a sua formulação e implementação. Por fim, avalia-se de que maneira a gestão do Plano de Manejo da APA de Pouso Alto contribuiu para a produção de uma gestão territorial ineficaz por parte do poder público.

\section{METODOLOGIA}

Este trabalho foi estimulado pelo documentário "Ser tão velho Cerrado", dirigido por André D’Elia e lançado em 2018. Após isso, foi realizado a partir de levantamento 
bibliográfico de artigos científicos e capítulos de livros encontrados no banco de dados "Google Acadêmico". Para realizar a seleção das bibliografias foram feitas buscas na plataforma com as palavras-chave: "políticas públicas ambientais"; "Chapada dos Veadeiros"; "plano de manejo"; "APA"; "unidade de conservação". A plataforma gerou um resultado total de 794 artigos, porém apenas 10 foram selecionados por contemplarem a temática associada, além de obras clássicas sobre políticas públicas.

Também utilizou-se da legislação ambiental, mais especificamente do Sistema Nacional de Unidades de Conservação (SNUC) e das leis 9.985/2000 e 9985/2000, dos $\operatorname{artigos} 4^{\circ}$ e $27^{\circ}$, respectivamente, como contribuição para a discussão apresentada. Somado a isso, análise de dados dos relatos e a revisão do próprio Plano de Manejo da APA de Pouso Alto contribuíram para a construção dos resultados deste artigo.

\section{RESULTADOS E DISCUSSÃO}

\section{A. POLÍTICA AMBIENTAL BRASILEIRA}

A relação do Brasil com o seu meio ambiente data desde sua época colonial quando tinha o papel fundamental de fornecer recursos naturais de fonte extrativista para a sua colônia portuguesa, associada, essencialmente, ao seu uso econômico. Entretanto, foi apenas na década de 20 que se iniciou uma preocupação governamental quanto a legislação ambiental, formalizada em 1934 com o Código Florestal. A medida tratava as florestas como bem comum e instituía a restrição do uso de propriedades rurais, priorizando a proteção de ecossistemas. Data-se também, em 1937 e 1939 as primeiras unidades de conservação, o Parque Nacional de Itatiaia e os de Iguaçu e Serra dos Órgãos, respectivamente (Ramos, 2012).

O que se observou ao longo do tempo, foi o aprimoramento das políticas de cunho ambiental, influenciada pelo debate internacional e eventos pontuais, como a Conferência de Estocolmo em 1972 e a Eco-92. O crescimento da notoriedade do conceito de desenvolvimento sustentável aprimorou a relação entre homem e natureza, influenciando em políticas de uso sustentável no Brasil. Com isso, observou-se a criação de diversas instituições com preocupações ambientais, como foi o caso da Secretaria Especial do Meio Ambiente (SEMA) em 1973 que criou a Política Nacional do Meio Ambiente (PNMA) com Lei $n^{\circ}$ 6.938/81. Além disso, também foi criado o Sistema Nacional de Meio Ambiente (SISNAMA), atuando na articulação dos órgãos das três esferas 
governamentais na gestão ambiental. Esse sistema possui o Ministério do Meio Ambiente (MMA) como órgão central, o Conselho Nacional do Meio Ambiente (Conama) como órgão consultivo e deliberativo, órgãos executores de autarquia da administração pública, como o Instituto do Meio Ambiente e Recursos Naturais Renováveis (Ibama) e Instituto Chico Mendes de Conservação e Biodiversidade (ICMBio) e, por fim, os órgãos municipais e estaduais na execução de programas, controle e fiscalização.

Paralelo a isso, o aumento das discussões ambientais e das unidades de conservação propiciaram a criação do Sistema Nacional de Unidade de Conservação (SNUC), aprovado em 2000 pela Lei n 9.985, seguindo os mesmos órgãos gestores do SISNAMA. A inovação do SNUC é a qualificação das unidades de conservação em diferentes tipologias, além de definir a atuação nas coordenações de cada um dos três poderes e formalizar a integração entre as demais unidades adjacentes. Pretende-se, assim, também assegurar amostras ecológicas para o uso da população. Como destaque, o SNUC determina a obrigatoriedade de um Plano de Manejo para cada unidade de conservação, elaborado em função dos objetivos gerais da unidade, junto ao seu zoneamento e uso do solo. Segundo o art. $4^{\circ}$ da Lei 9.985/2000, destacam-se os seguintes objetivos:

I - contribuir para a manutenção da diversidade biológica e dos recursos genéticos no território nacional e nas águas jurisdicionais;

II - proteger as espécies ameaçadas de extinção no âmbito regional e nacional; III - contribuir para a preservação e a restauração da diversidade de ecossistemas naturais;

IV - promover o desenvolvimento sustentável a partir dos recursos naturais;

V - promover a utilização dos princípios e práticas de conservação da natureza no processo de desenvolvimento;

VI - proteger paisagens naturais e pouco alteradas de notável beleza cênica;

VII - proteger as características relevantes de natureza geológica, geomorfológica, espeleológica, arqueológica, paleontológica e cultural;

VIII - proteger e recuperar recursos hídricos e edáficos;

IX - recuperar ou restaurar ecossistemas degradados;

$\mathrm{X}$ - proporcionar meios e incentivos para atividades de pesquisa científica, estudos e monitoramento ambiental;

XI - valorizar econômica e socialmente a diversidade biológica;

XII - favorecer condições e promover a educação e interpretação ambiental, a recreação em contato com a natureza e o turismo ecológico;

XIII - proteger os recursos naturais necessários à subsistência de populações tradicionais, respeitando e valorizando seu conhecimento e sua cultura e promovendo-as social e economicamente. (SNUC, 2000)

Desse modo, o SNUC qualifica as unidades de conservação em dois grandes grupos, as de uso integral e as de uso sustentável. As primeiras têm o intuito de preservar a natureza e são mais restritivas, admitindo apenas o uso indireto de seus recursos 
naturais. São elas: Estação Ecológica, Reserva Biológica, Parque Nacional, Refúgio de Vida Silvestre e Monumento Natural. Já as de uso sustentável permitem o uso de seus recursos naturais de forma sustentável conciliando com a conservação da natureza. E se subdividem em: Área de Proteção Ambiental, Área de Relevante Interesse Ecológico, Floresta Nacional, Reserva Extrativista, Reserva de Fauna, Reserva de Desenvolvimento Sustentável e Reserva Particular do Patrimônio Natural (ICMBio).

\section{B. APA DE POUSO ALTO: CONFLITOS TERRITORIAIS E GESTÃO DO PLANO DE MANEJO}

O cerrado, conhecido também como a savana brasileira, é a formação ambiental mais antiga do território brasileiro, concretizado há 45 milhões de anos e localizado no Centro-Oeste do país. Considerado como uma das mais ricas biodiversidades do mundo, é um hotspot mundial com uma fauna e flora especializadas e organismos sobreviventes de mudanças climáticas. Encontra-se no estágio de seu clímax evolutivo, ou seja, sua extinção é irreversível, caso extinto é impossível que se recupere em totalidade. Além disso, por sua posição geográfica em planalto, é nomeado o guarda-chuva do Brasil por ser o berço da água de outras três grandes bacias da América Latina: Bacia do TocantinsAraguaia, Bacia do Rio da Prata e Bacia do São Francisco (QUEIROZ, 2018).

A presença de comunidades tradicionais no Centro-Oeste é um dos principais fatores que explica a existência de unidades de conservação de uso sustentável na região. Uma das maiores comunidades quilombolas do país, o quilombo Kalunga com aproximadamente 6.000 habitantes, ocupa uma área de 253.200 hectares. Em 1991, o governo de Goiás reconheceu seu território como Sítio Histórico e Patrimônio Cultural Kalunga. Tal reconhecimento é considerado uma conquista da luta e resistência desse povo no território que abriga fitofisionomias de cerrado nativo, demonstrando o potencial de conservação ambiental por parte dessa comunidade.

Outro ponto importante para a discussão é a presença do Parque Nacional da Chapada dos Veadeiros na nossa área de análise. O Parque Nacional do Tocantins, atual Parque Nacional da Chapada dos Veadeiros, foi criado em 1961 por Juscelino Kubitschek abrigando 625 mil hectares de área protegida. Reduzido a 65 mil hectares por projetos governamentais do estado de Goiás, a implementação do parque foi palco de conflitos socioambientais entre as comunidades tradicionais, que foram alocadas para seu entorno, já que se trata de uma unidade de conservação de uso integral. 
Além disso, a população local teve suas atividades econômicas altamente degradadoras do meio ambiente, como a mineração e a agropecuária, desarticuladas.

Apoiando-se no discurso preservacionista dos Estados Unidos, Diegues (2004) critica de forma bem didática, como a construção de parques nacionais interfere na vida dos povos que já se encontravam dentro desses territórios. É exposta, então, como essa ideia de áreas protegidas sem interferência humana é fraca e refutável quando transposta para a realidade brasileira ao relembrar a comunidade Kalunga. Diegues aponta a importância do papel das comunidades tradicionais na conservação das áreas protegidas através dos conhecimentos e manejos tradicionais, sendo estas essenciais para a conservação da biodiversidade.

Os impactos socioecológicos ascendentes dentro das comunidades tradicionais é produto da lógica de capital que tomadores de decisão insistem em se fundar. No caso do Quilombo Kalunga, os moradores que viviam dentro do que é hoje o Parque Nacional da Chapada dos Veadeiros foram alocados às áreas pertencentes ao que é a atual APA de Pouso Alto, exercendo atividades econômicas que respeitem as cláusulas destas unidades de conservação, a exemplo do ecoturismo principal atividade. Apesar de existir a demarcação do território, muitos quilombolas não possuem suas terras protegidas por estarem localizadas à margem do território legalizado.

A APA de Pouso Alto, é concebida como uma zona de amortecimento do Parque Nacional. Tal estratégia é defendida pelo SNUC para que os objetivos das UCs em questão não sejam comprometidos pelas consequências da degradação de suas áreas de limite. Isto demonstra a importância de haver o diálogo entre os tomadores de decisão das duas unidades de conservação, uma vez que são classificadas de formas diferentes, mas possuem como objetivos comuns a perpetuação do bioma Cerrado, a valorização dos saberes tradicionais e a qualidade de vida dos moradores locais.

A APA de Pouso Alto, classificada como uma unidade de conservação de uso sustentável, então, torna-se imprescindível para manutenção desde bioma. Criada pela Decreto $\mathrm{N}^{\mathrm{o}} 5.419$ em maio de 2001, possui 872 mil hectares e localiza-se na microrregião da Chapada dos Veadeiros, ocupando, aproximadamente, 2,3\% do estado de Goiás. Percorre por seis municípios do nordeste goiano, sendo eles Alto Paraíso de Goiás, Cavalcante, Teresina de Goiás, Colinas do Sul, São João d'Aliança e Nova Roma. 
Figura 1 - Municípios da Unidade de Conservação APA de Pouso Alto, Goiás.

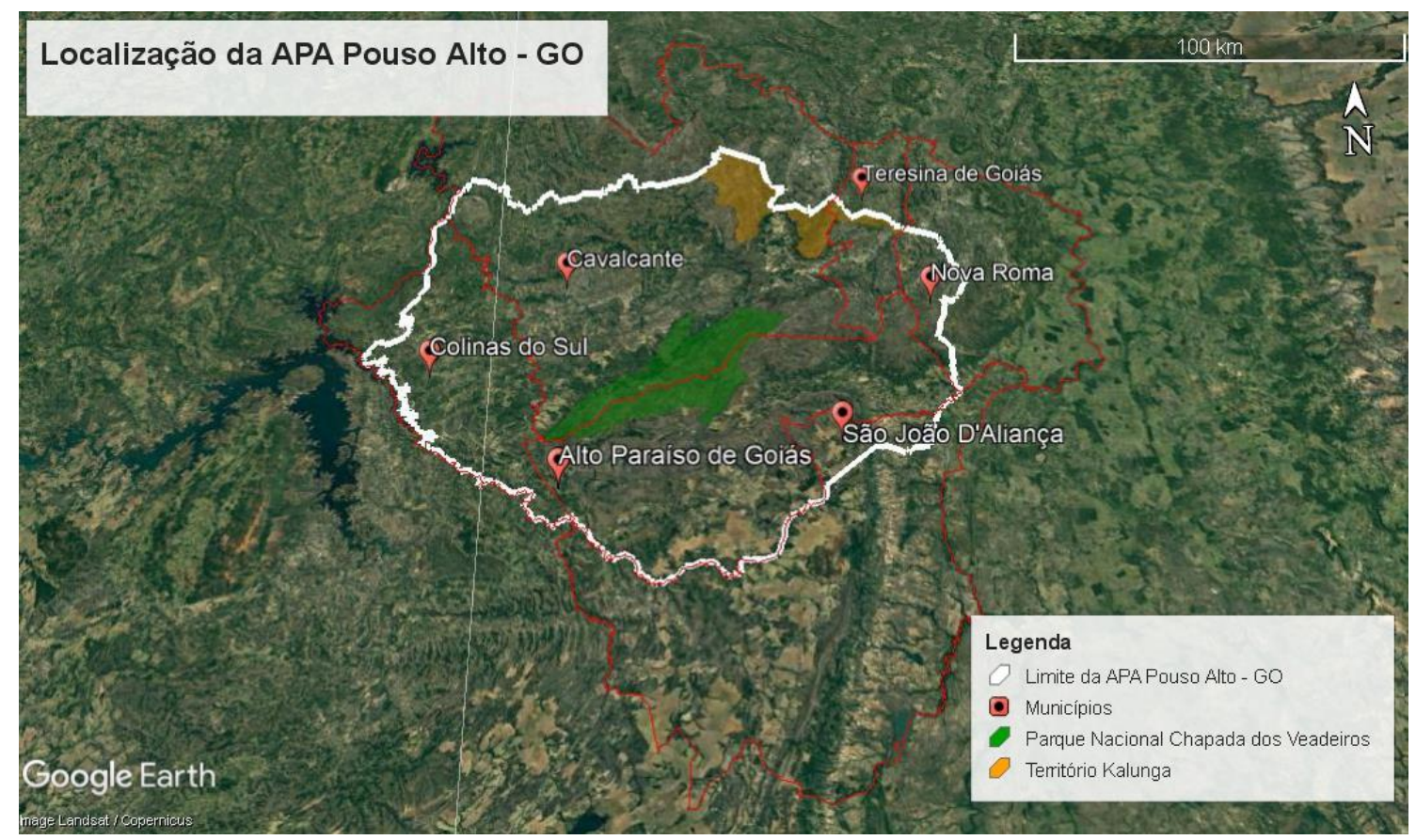

Fonte: SIEG e Secretaria de Estado de Meio Ambiente e Desenvolvimento Sustentável - Governo do Estado de Goiás.

Segundo Meiçó (2006), a discussão sobre a criação da APA foi dada em 2000 por meio de uma consulta popular aos moradores da região a partir dos problemas de gestão territorial apresentados e o almejo de possíveis benefícios enquanto unidade de conservação. Em 2001, o número estimado de moradores era de 53 mil, entretanto, apenas 150 pessoas participaram desta consulta pública. Apesar do SNUC não determinar o número de consultores mínimos necessários, é esperado que pessoas representativas da região participem, já que a APA é uma UC de uso sustentável com o intuito de prezar pela proteção da qualidade de vida e o bem-estar dos moradores tradicionais locais. Além da troca de informações inteligíveis e adequadas do Poder Público direcionadas a população local. Porém, moradores dos municípios não acreditam que a sua representatividade tenha sido a desejável, implicando em considerações sobre o uso sustentável da APA e sobre a sua gestão territorial.

Ampliado a esse descompasso, a APA de Pouso Alto conta com sobreposições de diferentes unidades de conservação, como o Parque Nacional da Chapada dos Veadeiros, a Reserva da Biosfera da Chapada dos Veadeiros, parte da terra indígena dos Avá Canoeiros, oito Reservas Particulares do Patrimônio Natural, além de comunidades tradicionais, como o Quilombo Kalunga. A quantidade de diferentes tipologias 
conservacionistas e a consequente divergência de interesses entre tais áreas demonstra a dificuldade na elaboração do Plano de Manejo da APA.

O Plano de Manejo é um documento técnico que devem conter as principais diretrizes da referida unidade, estabelecendo seu ordenamento territorial e zoneamento, além das normas quanto ao uso da área e o manejo dos recursos naturais (GOIÁS, 2016). Segundo o artigo 27 do SNUC (Lei 9985/00), o Plano de Manejo é obrigatório para cada unidade de conversação e deve ser realizado em até 5 anos de sua criação. De acordo com a Lei 9985/00: Manejo.

Art. 27. As unidades de conservação devem dispor de um Plano de $\S 1^{\circ} \mathrm{O}$ Plano de Manejo deve abranger a área da unidade de conservação, sua zona de amortecimento e os corredores ecológicos, incluindo medidas com o fim de promover sua integração à vida econômica e social das comunidades vizinhas.

$\S 2^{\circ} \mathrm{Na}$ elaboração, atualização e implementação do Plano de Manejo das Reservas Extrativistas, das Reservas de Desenvolvimento Sustentável, das Áreas de Proteção Ambiental e, quando couber, das Florestas Nacionais e das Áreas de Relevante Interesse Ecológico, será assegurada a ampla participação da população residente.

$\S 3^{\circ} \mathrm{O}$ Plano de Manejo de uma unidade de conservação deve ser elaborado no prazo de cinco anos a partir da data de sua criação.

$\S 4^{\circ} \mathrm{O}$ Plano de Manejo poderá dispor sobre as atividades de liberação planejada e cultivo de organismos geneticamente modificados nas Áreas de Proteção Ambiental e nas zonas de amortecimento das demais categorias de unidade de conservação, observadas as informações contidas na decisão técnica da Comissão Técnica Nacional de Biossegurança - CTNBio sobre: (Incluído pela Lei $\mathrm{n}^{\circ} 11.460$, de 2007)

I - o registro de ocorrência de ancestrais diretos e parentes silvestres; (Incluído pela Lei n ${ }^{\circ} 11.460$, de 2007)

II - as características de reprodução, dispersão e sobrevivência do organismo geneticamente modificado; (Incluído pela Lei $\mathrm{n}^{\circ} 11.460$, de 2007)

III - o isolamento reprodutivo do organismo geneticamente modificado em relação aos seus ancestrais diretos e parentes silvestres; e (Incluído pela Lei n ${ }^{\circ}$ 11.460, de 2007)

IV - situações de risco do organismo geneticamente modificado à biodiversidade. (Incluído pela Lei $\mathrm{n}^{\circ} 11.460$, de 2007) (BRASIL, 2000, grifo nosso)

Entretanto, o projeto de criação do Plano de Manejo da APA de Pouso Alto só foi iniciado em 2005, quase 5 anos após a sua implementação. Até este momento, insatisfações quanto às medidas do "Corte Zero" em 2004, que proibia o corte e a supressão da vegetação primária e secundária da APA, já indicavam conflitos anteriores entre os moradores da região. Assim, a Agência Goiana de Meio Ambiente (AGMA), responsável pela elaboração do plano contratou em primeiro momento uma empresa de Porto Alegre, Boursheid, que começou seu trabalho de levantamento de dados técnicos 
na ausência de qualquer órgão consultivo local. Apesar do SNUC não determinar o prazo limite para a criação de conselhos locais, é dito que estes devem participar dos processos de elaboração, implementação e revisão do Plano de Manejo (MEIÇÓ, 2006).

Relatos de moradores alegam que quando consultados, os avisos de reuniões e encontros não eram eficazes, já que eram informados muitas vezes no dia anterior. Além disso, houve muitas críticas quanto a empresa contratada para a elaboração, visto que ela é originária da Região Sul do país, desconhecendo especificidades do local. Bem retratado do documentário "Ser Tão Velho Cerrado", o processo de criação do plano foi marcado por intensas e inesgotáveis disputas, resumidamente dicotomizadas entre ruralistas e moradores locais.

Além da comunidade tradicional, a ressignificação dos territórios em unidades de conservação prejudicou grandes mineradores e ruralistas que exerciam suas atividades econômicas. Apesar das problemáticas ambientais serem reconhecidas, a mineração feita de forma não predatória, por exemplo, é vista pela prefeitura e pelos mineradores enquanto essencial para o desenvolvimento local. Como dito anteriormente, o Corte Zero não foi bem aceito e, assim como os mineradores, os ruralistas não pararam suas atividades. Embora a sociedade tradicional possua importante papel a fim de minimizar os problemas socioambientais, aqueles que se adequaram às novas leis de restrição precisam de incentivo para exercer o ecoturismo, considerado o setor que mais emprega e distribui renda nos municípios atingidos.

Segundo estas constatações e a diversidade cultural da região, é evidente que a implementação dessas unidades de conservação provocaria diversos conflitos ideológicos entre ruralistas, mineradores, população local, comunidades tradicionais e a prefeitura. E, consequentemente, para a elaboração e gestão do respectivo Plano de Manejo, como demonstrado em 2017 na conquista de ampliação da área do PNCV. Tal ampliação não foi bem recebida por todos e incentivou a ocorrência de incêndios criminosos por aqueles indivíduos que tiveram suas terras desapropriadas em virtude dessa expansão, por exemplo.

Por fim, entre diversas disputas, o Plano de Manejo da APA de Pouso Alto foi lançado apenas em 2016 com 7 encartes e um referendo de 2017. O final de sua elaboração foi assumido pelo Centro Tecnológico de Engenharia Ltda da cidade de Brasília, devido às intensas críticas à empresa porto-alegrense. Hoje apresenta o Conselho 
Consultivo da APA de Pouso Alto (CONAMA) com 40 representantes e subdivisões em diversos Grupos de Trabalho. A demora na elaboração do Plano, além de ter se dado por conflitos entre os seus gestores, também decorre das dificuldades em aprimorar as diretrizes do Plano de Manejo do Parque Nacional da Chapada dos Veadeiros, essencial para a instituição da APA.

Conforme estabelecido pelo SNUC, a participação efetiva das populações locais na criação, implantação e gestão dessas áreas é imprescindível para a gestão participativa das unidades de conservação. $\mathrm{O}$ conselho gestor, formado por representantes de órgãos públicos e de organizações da sociedade civil, é responsável pelo debate sobre a política pública instituída, além de definir as prioridades da gestão. A conservação da biodiversidade é então implementada através do plano de manejo, documento que define as ações a serem executadas na unidade de conservação. Por ser a instância legítima para a ação crítica, fiscalizadora e consultiva do acompanhamento das atividades de gestão da unidade de conservação, os conselhos gestores devem priorizar a gestão participativa, que deve ser inclusiva ao promover a integração econômica, social, ambiental e cultural das comunidades vizinhas (BEZERRA et al., 2018).

Tendo como pressuposto que "a gestão é um processo participativo, integrado e contínuo, que visa promover a compatibilização das atividades humanas com a qualidade e a preservação do patrimônio ambiental" (SECRETARIA DO MEIO AMBIENTE, 2011) é necessário que além do aprimoramento e criação de instrumentos e ferramentas que se adequem às práticas de gestão ambiental, seja estimulado o empoderamento e o exercício do controle social das políticas públicas direcionadas à gestão de unidades de conservação (BEZERRA et al., 2018). De acordo com os autores:

\footnotetext{
"Considerando, então, que o Estado se constitui um espaço de negociação onde o reconhecimento social de um problema e sua priorização enquanto ação de governo está relacionada à capacidade de barganha da sociedade e às pressões exercidas sobre ele, as questões ambientais não escapam desta lógica. As decisões sobre a política ambiental pública estão relacionadas ao processo de barganha e à correlação de forças que se estabelece na sociedade e os interesses a elas vinculados. Para que isso aconteça a participação social na gestão de unidades de conservação é fundamental para garantir as necessidades da população local e as prioridades de conservação e, assim, a sustentabilidade da gestão.” (BEZERRA et al., 2018)
}

Nesse sentido, pode-se perceber que apesar do conselho gestor atual da APA de Pouso Alto ser composto por diferentes grupos da sociedade civil, está comprometido com as atividades do agronegócio, havendo uma disputa de poderes assimétrica. A falta 
de representatividade, principalmente das comunidades tradicionais, comprova que mesmo com o esforço de integrar a participação social nos conselhos, se não houver a descentralização das decisões, não será possível alcançar a democracia. Consequentemente, também não há possibilidade de fortalecimento e ampliação de conhecimentos sobre os recursos naturais que estão protegidos e a importância de mantêlos protegidos será negligenciada.

Como resultado desta desequilibrada balança de poder na gestão do Plano, a APA é palco de cenários controversos quanto a sua real implementação. A maior fronteira agrícola do mundo - Matopiba -, região que compreende Maranhão, Tocantins, Piauí e Bahia apresenta expressiva produção da economia nacional, porém, intensifica a desigualdade em alguns municípios. A Fazenda Gavião, que pertence ao pai do governador do estado de Goiás, está situada nos limites da APA produzindo soja transgênica e impactando os ecossistemas. Além dos incêndios criminosos que aconteceram em 2017 na Chapada dos Veadeiros, o ano de 2020 está sendo marcado pelo fogo na região do Centro-Oeste brasileiro.

No cenário atual, o que se tem, então, é uma política pública ambiental materializada pela APA de Pouso Alto estremecida quanto às relações de poder e influências territoriais. Mesmo após a implementação de seu Plano de Manejo, a gestão da unidade de conservação continua perturbada pela ausência de reconhecimento das populações tradicionais e da etapa de fiscalização. Os exemplos expostos anteriormente ilustram a negligência por parte do Estado, uma vez que ninguém foi penalizado pela execução desses crimes ambientais. Por isso, é necessário implementar medidas que contemplem as realidades sobre o conjunto do território, entendido em sua pluralidade, para além de um olhar dirigido a grupos sociais ou setores econômicos específicos.

\section{CONSIDERAÇÕES FINAIS}

A implementação de unidades de conservação pelo SNUC apresenta alguns desafios quanto a sua gestão territorial. A sobreposição de diversas UCs e a pressão de diferentes grupos de interesse são recorrentes em diversos territórios de interesse preservacionista. No caso empírico analisado, a APA de Pouso Alto é um exemplo onde as forças de ruralistas sobressaem no jogo de poder assimétrico com as comunidades tradicionais. Consequente a isso, observa-se a capital brasileira secando e a Chapada dos Veadeiros tornando-se o novo berço agrícola do país. Tem-se aqui o primeiro 
questionamento sobre até que ponto a APA pode ser considerada uma unidade de conservação de uso sustentável, já que não contempla a manutenção da biodiversidade e das multiculturalidades.

Este fato nos abre um pressuposto para analisar a ineficácia desta política pública ambiental. Desde a dificuldade de simetria na gestão do seu Plano de Manejo até a falta de fiscalização, passando pela importância da gestão participativa, observa-se a negligência de ação do Estado. Ao falar de políticas públicas, espera-se que o governo aja na proposta de mudanças pensadas para a garantia de direitos dos cidadãos, entretanto, apesar de previsto pelo SNUC, a gestão social participativa da APA não se concretiza e assume uma postura empresarial e parcial. Como bem salientado por Tenório e Saravia:

\footnotetext{
"A qualificação gestão social, agregaria valores democráticos à gestão pública, na medida que esta deveria atuar levando em consideração que o seu processo de tomada de decisão deve ser executado levando em conta a soberania popular, ou seja, por meio de ações concertadas com a cidadania de modo dialógico. A gestão social, portanto, não deve ser apenas a prática de uma gestão pública voltada ou preocupada com a solução de problemas sociais como muitos idealizam, mas uma prática gerencial que incorpore a participação da sociedade no processo de planejamento e implementação de políticas públicas. Não basta agir para o social, mas agir com o social. Gestão pública é o fim e gestão social, o meio." (TENÓRIO e SARAVIA, 2017)
}

A exemplo e a fim de conclusão quanto a análise desta política pública, têm-se a manchete de jornal do dia 25 de junho de 2020: "Prefeito de Cavalcante é multado em R\$ 169 mil e tem máquinas apreendidas por desmatar área nativa do Cerrado" (G1, 2020). Esta notícia torna-se emblemática ao tempo em que o próprio gestor local infringe as diretrizes por ele organizadas, além de seu grau de influência. Dessa forma, diante do que foi exposto, a real problemática que incentivou a criação da agenda desta política pública ambiental permanece, tornando a medida ineficaz para o controle da diversidade e sobrevivência do Cerrado.

\section{REFERÊNCIAS BIBLIOGRÁFICAS}

ARRETCHE, M. T. S. Tendências no estudo sobre avaliação. IN: RICO, Elizabeth Melo. Avaliação de Políticas Sociais: uma questão em debate. $6^{\text {a }}$. edição. São Paulo, Cortez: Instituto de Estudos Especiais, 2009.

ARRETCHE, M. T. S. Uma contribuição para fazermos avaliações menos ingênuas. In: BARREIRA e CARVALHO (org.) Tendências e perspectivas na avaliação de políticas e programas sociais. São Paulo: IEE/PUC-SP, 2001

BEZERRA, G. S. C. L.; CARVALHO, R. M. C. M. O.; LYRA, M. R. C. C.; FRUTuOSO, N. M. A.; BRANDÃO, S. S. F. Política Pública e o desafio da participação social na gestão de unidades de conservação. HOLOS, Ano 34, Vol. 06, 
2018.

DIEGUES, A. C. Saberes tradicionais e etnoconservação. In: Diegues, A. C. \& Viana, V. M. (Orgs.). Ed. HUCITEC. pp. 9-22. 2004.

GOIÁS. Plano de Manejo APA de Pouso Alto. Resumo Executivo, 2016. Disponível em:

<https://www.meioambiente.go.gov.br/images/imagens_migradas/upload/arquivos/2016 -06/resumo-executivo.pdf> . Acesso em 30 de junho de 2020.

ICMBio. SNUC. Sistema Nacional de Unidades de Conservação. 2000.

MARQUES, E. As políticas públicas na ciência política. In: MARQUES, Eduardo Cesar Leão; FARIA, Carlos Aurélio Pimenta de (Org.). A Política Pública como Campo Multidisciplinar. São Paulo: Editora Unesp; Rio de Janeiro: Editora Fiocruz/CEM, 2013 MEIÇO, C. A. Caracterização dos Atores Presentes no Contexto de Implementação da APA do Pouso Alto - GO: Descrição de seus Valores e do Capital Social. Dissertação de Mestrado. Centro de Desenvolvimento Sustentável - Universidade de Brasília. Brasília, 2006.

QUEIROZ, J. J. R. Áreas de Preservação Permanente estratégicas para os recursos hídricos na APA de Pouso Alto: panorama, técnicas e custos para restauração. Trabalho de Conclusão de Curso. Centro UNB Cerrado - Universidade de Brasília. Alto Paraíso de Goiás, 2018.

SABBAGH, R. B. Gestão ambiental. In: Cadernos de Educação Ambiental, 16. Secretaria do Meio Ambiente, São Paulo: SMA, 176p. 2011

SANTANA, Vitor. Prefeito de Cavalcante é multado em R\$ 169 mil e tem máquinas apreendidas por desmatar área nativa do Cerrado. G1, 26 de junho de 2020, Goiás. Disponível em: <https://g1.globo.com/go/goias/noticia/2020/06/25/prefeito-decavalcante-e-multado-em-r-169-mil-e-tem-maquinas-apreendidas-por-desmatarcerrado-virgem.ghtml> Acesso em: 05 de julho de 2020.

SANTOS, E. L., CAÍRES, F. C. B., SANTANA, W. G. P., BATISTA, F. S. S. Análise de Políticas Públicas: a Experiência do ProJovem Urbano na Cidade de Vitória da Conquista - Ba. XXXV Encontro da ANPAD, Rio de Janeiro, 4 a 7 de setembro de 2011. SER tão velho Cerrado. Direção: André D'Elia. Brasil: O2 Filmes, 2018. Netflix.

SILVA, T. C. B. Regime Jurídico das Unidades de Conservação: a implantação da Área de Proteção Ambiental do Pouso Alto e do Parque Nacional da Chapada dos Veadeiros e suas implicações. Trabalho de Conclusão de Curso. Centro de Estudos do Cerrado da Chapada dos Veadeiros - Universidade de Brasília. Alto Paraíso de Goiás, 2018.

SOUZA, C. Políticas públicas: questões temáticas e de pesquisa. In: CADERNO CRH, Salvador, n. 39, p. 11-24, jul./dez. 2003.

SOUZA, C. Políticas Públicas: uma revisão da literatura. In: Sociologias, Porto Alegre, ano 8, no 16, jul/dez 2006, p. 20-45.

TENÓRIO, F, G; SARAVIA, E, J. Esforços sobre gestão pública e gestão social.: as recentes reformas do Estado. In: MARTINS, Paulo Emilio Mattos e PIERANTI, Octavio Penna. Estado e Gestão Pública. Visões do Brasil Contemporâneo. Rio de Janeiro: Editora da FGV, 2006, p.107- 132. 